Buletin Ilmiah Mat. Stat. dan Terapannya (Bimaster)

Volume 08, No. 1 (2019), hal 53 - 62.

\title{
TRANSFORMASI LAPLACE MODIFIKASI UNTUK MENYELESAIKAN BEBERAPA PERSAMAAN DIFERENSIAL BIASA LINEAR
}

\author{
Yusnanda, Helmi, Yudhi
}

\section{INTISARI}

\begin{abstract}
Transformasi Laplace merupakan salah satu jenis transformasi integral yang dapat menyelesaikan berbagai persamaan diferensial biasa linear. Tetapi pada persamaan diferensial biasa linear dengan koefisien variabel, Transformasi Laplace hanya dapat menyelesaikan beberapa persamaan diferensial tertentu. Tujuan dari penelitian ini adalah untuk memodifikasi Transformasi Laplace menjadi sebuah transformasi integral yang baru sehingga dapat menyelesaikan persamaan diferensial yang sebelumnya tidak dapat diselesaikan dengan Transformasi Laplace. Penyelesaian persamaan diferensial biasa linear dengan metode Transformasi Laplace modifikasi dilakukan dengan cara mentransformasikan persamaan diferensial menjadi sebuah fungsi dalam variabel transformasi. Fungsi tersebut kemudian ditransformasikan dengan invers Transformasi Laplace modifikasi agar diperoleh penyelesaian dari persamaan diferensial yang diberikan. Hasil penelitian ini menunjukkan bahwa Transformasi Laplace modifikasi dapat menyelesaikan beberapa persamaan diferensial biasa linear yang tidak dapat diselesaikan dengan Transformasi Laplace.
\end{abstract}

Kata kunci: persamaan diferensial biasa linear, Transformasi Laplace modifikasi

\section{PENDAHULUAN}

Transformasi integral merupakan salah satu teknik yang berguna dalam menyelesaikan persamaan diferensial. Pada prinsipnya transformasi integral dilakukan dengan membawa persamaan diferensial ke ruang hasil transformasi menjadi sebuah fungsi dalam variabel transformasi. Fungsi tersebut kemudian dikembalikan ke ruang asal dengan melakukan invers transformasi integral sehingga mendapatkan solusi dari persamaan diferensial yang dimaksud [1,2].

Transformasi integral sendiri dimulai dengan munculnya Transformasi Fourier yang kemudian diikuti oleh transformasi Laplace pada tahun 1822 yang merupakan turunan dari Transformasi Fourier [1]. Transformasi Laplace dapat menyelesaikan berbagai persamaan diferensial termasuk persamaan diferensial biasa linear. Tetapi tidak semua persamaan diferensial dapat diselesaikan dengan Transformasi Laplace. Pada persamaan diferensial biasa dengan koefisien variabel untuk masalah nilai awal dan nilai batas, terdapat beberapa persamaan diferensial yang tidak dapat diselesaikan dengan Transformasi Laplace.

Penelitian ini memodifikasi Transformasi Laplace agar dapat menyelesaikan persamaan diferensial yang sebelumnya tidak dapat diselesaikan dengan Transformasi Laplace. Berdasarkan uraian tersebut maka tujuan pada penelitian ini adalah membentuk transformasi integral yang diperoleh dari memodifikasi Transformasi Laplace, menganalisis sifat-sifat yang berlaku pada Transformasi Laplace modifikasi serta menganalisis bentuk persamaan diferensial yang dapat diselesaikan oleh Transformasi Laplace modifikasi. Persamaan diferensial yang digunakan dalam penelitian ini yaitu persamaan diferensial biasa linear hingga orde ketiga.

Langkah-langkah yang dilakukan dalam penelitian ini dimulai dengan menentukan bentuk Transformasi Laplace modifikasi dan diterapkan pada beberapa fungsi dasar serta menentukan sifatsifat dasar dari Transformasi Laplace modifikasi. Dari sifat-sifat dasar tersebut dapat ditentukan hasil transformasi integral pada persamaan diferensial biasa linear baik dengan koefisien konstan maupun dengan koefisien variabel. Langkah selanjutnya adalah menyelesaikan persamaan diferensial biasa linear dengan koefisien konstan dan koefisien variabel yang dapat diselesaikan dengan Transformasi Laplace modifikasi. Dengan mentransformasikan persamaan diferensial dengan Transformasi Laplace 
modifikasi, persamaan diferensial hasil transformasi tersebut disederhanakan menjadi sebuah fungsi dalam variabel transformasi. Jika persamaan diferensial hasil transformasi tidak dapat disederhanakan maka persamaan diferensial yang diberikan tidak dapat diselesaikan dengan menggunakan Transformasi Laplace modifikasi. Jika persamaan diferensial hasil transformasi dapat disederhanakan, langkah selanjutnya fungsi tersebut dibawa ke dalam ruang asalnya dengan menerapkan kebalikan atau invers dari Transformasi Laplace modifikasi sehingga mendapatkan solusi yang tepat untuk persamaan diferensial yang diberikan.

\section{TRANSFORMASI LAPLACE}

Transformasi Laplace merupakan salah satu jenis transformasi integral yang dapat menyelesaikan berbagai persamaan diferensial biasa linear. Transformasi Laplace secara umum didefinisikan oleh

$$
\mathcal{L}\{f(t)\}=F(s)=\int_{0}^{\infty} e^{-s t} f(t) d t,
$$

dengan $e^{-s t}$ merupakan fungsi kernel transformasi dan $s$ merupakan variabel transformasi dalam $\mathbb{R}^{+}$ [1,2,3]. Berdasarkan Persamaan (1), Transformasi Laplace dapat mentransformasikan beberapa persamaan fungsi-fungsi sederhana seperti pada Contoh 1 .

Contoh 1 Transformasi Laplace pada beberapa fungsi sederhana.

1. Jika $f(t)=1$ untuk $t>0$, maka

$$
\begin{aligned}
F(s) & =\mathcal{L}\{1\}=\int_{o}^{\infty} e^{-s t} d t=\lim _{A \rightarrow \infty} \int_{O}^{A} e^{-s t} d t=\lim _{A \rightarrow \infty}-\left.\frac{1}{s} e^{-s t}\right|_{0} ^{A} \\
& =\lim _{A \rightarrow \infty}\left[-\frac{1}{s} s^{-s A}+\frac{1}{s} s^{-s .0}\right]=\frac{1}{s} .
\end{aligned}
$$

2. Jika $f(t)=e^{a t}$, dengan $a$ adalah konstan maka

$$
\begin{aligned}
& \mathcal{L}\left\{e^{a t}\right\}=F(s)=\int_{o}^{\infty} e^{a t} e^{-s t} d t=\lim _{A \rightarrow \infty} \int_{o}^{A} e^{-(s-a) t} d t=\lim _{A \rightarrow \infty}-\left.\frac{1}{s-a} e^{-(s-a) t}\right|_{0} ^{A} \\
= & \lim _{A \rightarrow \infty}\left[-\frac{1}{s-a} e^{-(s-a) A}+\frac{1}{s-a} e^{-(s-a) 0}\right]=\frac{1}{s-a} .
\end{aligned}
$$

3. Jika $f(t)=\sin a t$, dengan $a$ merupakan bilangan real konstan maka

$$
\begin{aligned}
\mathcal{L}\{\sin a t\}=F(s) & =\int_{0}^{\infty} e^{-s t} \sin a t d t=\frac{1}{2 i} \int_{0}^{\infty}\left[e^{-t(s-i a)}-e^{-t(s+i a)}\right] d t \\
& =\lim _{A \rightarrow \infty} \frac{1}{2 i} \int_{0}^{A}\left[e^{-t(s-i a)}-e^{-t(s+i a)}\right] d t=\frac{1}{2 i}\left[\frac{1}{s-i a}-\frac{1}{s+i a}\right]=\frac{a}{s^{2}+a^{2}} .
\end{aligned}
$$

4. Jika $f(t)=t^{n}$, dengan $n$ merupakan bilangan bulat positif, maka

$$
\begin{aligned}
\mathcal{L}\left\{t^{n}\right\} & =F(s)=\int_{o}^{\infty} e^{-s t} t^{n} d t=\lim _{A \rightarrow \infty} \int_{o}^{A} e^{-s t} t^{n} d t \\
& =\lim _{A \rightarrow \infty}\left[t^{n}\left(-\frac{1}{s} e^{-s t}\right)-\int_{o}^{A}\left(-\frac{1}{s} e^{-s t}\right) n t^{n-1} d t\right] \\
& =\left.\lim _{A \rightarrow \infty}\left[t^{n}\left(-\frac{1}{s} e^{-s t}\right)-n t^{n-1}\left(\frac{1}{s^{2}} e^{-s t}\right)-\cdots-\frac{n !}{s^{n+1}} e^{-s t}\right]\right|_{0} ^{A}=\frac{n !}{s^{n+1}} .
\end{aligned}
$$

Selain dapat mentransformasikan beberapa fungsi dasar, secara umum Transformasi Laplace memenuhi sifat dari operator linear yang dibuktikan pada Teorema 2.

Teorema 2 [1,2,3] Operator Transformasi Laplace $(\mathcal{L})$ dikatakan memenuhi operator linear jika terdapat fungsi $f: \mathbb{R}^{+} \rightarrow \mathbb{R}$ dan $g: \mathbb{R}^{+} \rightarrow \mathbb{R}$ yang dapat ditransformasikan oleh Transformasi Laplace dan memenuhi persamaan

$$
\mathcal{L}\{\alpha f(t) \pm \beta g(t)\}=\alpha \mathcal{L}\{f(t)\} \pm \beta \alpha \mathcal{L}\{g(t)\}
$$

dengan $\alpha$ dan $\beta$ merupakan konstanta bilangan real.

Selanjutnya diberikan beberapa sifat dasar dari Transformasi Laplace yang disajikan dalam Teorema 3 dan Teorema 4. 
Teorema 3 [1,2,3] Jika $\mathcal{L}\{f(t)\}=F(s)$, maka

1. $\mathcal{L}\left\{f^{\prime}(t)\right\}=s \mathcal{L}\{f(t)\}-f(0)=s F(s)-f(0)$

2. $\mathcal{L}\left\{f^{\prime \prime}(t)\right\}=s^{2} \mathcal{L}\{f(t)\}-s f(0)-f^{\prime}(0)=s^{2} F(s)-s f(0)-f^{\prime}(0)$, dan secara umum

3. $\mathcal{L}\left\{f^{(n)}(t)\right\}=s^{n} F(s)-s^{n-1} f(0)-s^{n-2} f^{\prime}(0)-\cdots-s f^{(n-2)}(0)-f^{(n-1)}(0)$.

dengan $f^{(r)}(0)$ merupakan nilai dari $f^{(r)}(t)$ pada $t=0, r=0,1, \ldots,(n-1)$ dan $n$ bilangan bulat positif.

Teorema 4 [1] Jika $\mathcal{L}\{f(t)\}=F(s)$, maka

1. $\mathcal{L}\{t f(t)\}=-\frac{d}{d s} F(s)$,

2. $\mathcal{L}\left\{t f^{\prime}(t)\right\}=-\frac{d}{d s}(s F(s)-f(0))$,

3. $\left.\mathcal{L}\left\{t f^{(n)}(t)\right)\right\}=-\frac{d}{d s}\left(s^{n} F(s)-\sum_{i=1}^{n} s^{n-i} f^{(i-1)}(0)\right)$,

4. $\mathcal{L}\left\{t^{2} f(t)\right\}=\frac{d^{2}}{d s^{2}} F(s)$,

5. $\mathcal{L}\left\{t^{2} f^{\prime}(t)\right\}=\frac{d^{2}}{d s^{2}}(s F(s)-f(0))$,

6. $\mathcal{L}\left\{t^{2} f^{(n)}(t)\right\}=\frac{d^{2}}{d s^{2}}\left(s^{n} F(s)-\sum_{i=1}^{n} s^{n-i} f^{(i-1)}(0)\right)$

dengan $n$ bilangan bulat positif.

\section{TRANSFORMASI LAPLACE MODIFIKASI}

Transformasi Laplace secara umum dapat ditulis seperti pada Persamaan (1)

$$
\mathcal{L}\{f(t)\}=F(s)=\int_{0}^{\infty} e^{-s t} f(t) d t .
$$

Jika Persamaan (1) dikalikan dengan $\frac{\sqrt{s}}{\sqrt{s}}$ maka diperoleh

$$
\begin{gathered}
\mathcal{L}\{f(t)\}=\frac{\sqrt{s}}{\sqrt{s}} \int_{0}^{\infty} e^{-s t} f(t) d t, \\
\sqrt{s} \mathcal{L}\{f(t)\}=\sqrt{s} \int_{0}^{\infty} e^{-s t} f(t) d t, \\
\sqrt{s} \mathcal{L}\{f(t)\}=\mathcal{L}_{M}\{f(t)\} .
\end{gathered}
$$

Notasi $\mathcal{L}_{M}\{f(t)\}$ merupakan Transformasi Laplace modifikasi yang didefinisikan sebagai berikut:

$$
\mathcal{L}_{M}\{f(t)\}=\sqrt{s} \int_{0}^{\infty} e^{-s t} f(t) d t,
$$

untuk $t>0$ dan $e^{-s t}$ merupakan fungsi kernel transformasi serta $s$ merupakan variabel transformasi dengan $s \in \mathbb{R}^{+}$. Berdasarkan Persamaan (2) maka diketahui terdapat hubungan antara Transformasi Laplace dengan Transformasi Laplace modifikasi yaitu memenuhi persamaan

$$
\sqrt{s} \mathcal{L}\{f(t)\}=\mathcal{L}_{M}\{f(t)\}
$$

Transformasi Laplace modifikasi didefinisikan untuk fungsi orde eksponensial dengan fungsi $f$ dalam sebuah himpunan $A$ yang didefinisikan dengan

$$
A=\left\{f(t): \exists M, a>0,|f(t)|<M e^{a t}, t \in[0, \infty)\right\},
$$

untuk sebuah fungsi yang diberikan dalam himpunan $A$ dan konstanta $M$ merupakan bilangan terbatas.

\section{SIFAT-SIFAT DASAR PADA TRANSFORMASI LAPLACE MODIFIKASI}

Selain dapat mentransformasikan beberapa fungsi sederhana yang konvergen, Transfromasi Laplace modifikasi juga memiliki sifat-sifat dasar yang ditunjukkan dalam beberapa teorema berikut.

Teorema 5 (Sifat Perkalian Konstanta) Diberikan sebuah konstanta $k$ bilangan real dan $T(s)$ adalah transformasi integral $\mathcal{L}_{M}\{f(t)\}$ dari fungsi $f(t)$ maka

\section{Bukti:}

$$
\mathcal{L}_{M}\{k f(t)\}=k T(s)
$$

$\mathcal{L}_{M}\{k \cdot f(t)\}=\sqrt{s} \int_{0}^{\infty} k f(t) e^{-s t} d t$ 


$$
\begin{aligned}
& =k \sqrt{s} \int_{0}^{\infty} f(t) e^{-s t} d t \\
& =k \mathcal{L}_{M}\{f(t)\}=k T(s) .
\end{aligned}
$$

Teorema 6 (Sifat Penjumlahan dan Pengurangan) Diberikan $T_{1}(s)$ dan $T_{2}(s)$ adalah transformasi integral $\mathcal{L}_{M}\{f(t)\}$ dari $f_{1}(t)$ dan $f_{2}(t)$ serta a dan b merupakan suatu konstanta bilangan real maka

Bukti:

$$
\mathcal{L}_{M}\left\{a f_{1}(t) \pm b f_{2}(t)\right\}=a \mathcal{L}_{M}\left\{f_{1}(t)\right\} \pm b \mathcal{L}_{M}\left\{f_{2}(t)\right\}=a T_{1}(s) \pm b T_{2}(s) .
$$

$$
\begin{aligned}
\mathcal{L}_{M}\left\{a f_{1}(t) \pm b f_{2}(t)\right\}= & \sqrt{s} \int_{0}^{\infty}\left(a f_{1}(t) \pm b f_{2}(t)\right) e^{-s t} d t \\
& =\sqrt{s} \int_{0}^{\infty}\left(a f_{1}(t) e^{-s t} \pm b f_{2}(t) e^{-s t}\right) d t \\
& =\sqrt{s} \int_{0}^{\infty} a f_{1}(t) e^{-s t} d t \pm \sqrt{s} \int_{0}^{\infty} b f_{2}(t) e^{-s t} d t \\
& =a \mathcal{L}_{M}\left\{f_{1}(t)\right\} \pm b \mathcal{L}_{M}\left\{f_{2}(t)\right\}=a T_{1}(s) \pm b T_{2}(s) .
\end{aligned}
$$

Teorema 7 (Sifat Diferensial) Diberikan $\mathcal{L}_{M}\{f(t)\}=T(s)$, maka transformasi integral $\mathcal{L}_{M}\{f(t)\}$ dari turunan $f(t)$ terhadap $t$ adalah

1. $\mathcal{L}_{M}\left\{f^{\prime}(t)\right\}=s T(s)-\sqrt{s} f(0)$,

2. $\mathcal{L}_{M}\left\{f^{\prime \prime}(t)\right\}=s^{2} T(s)-s \sqrt{s} f(0)-\sqrt{s} f^{\prime}(0)$,

3. $\mathcal{L}_{M}\left\{f^{(n)}(t)\right\}=s^{n} T(s)-\sqrt{s} \sum_{k=1}^{n} s^{n-k} f^{(k-1)}(0)$.

\section{Bukti:}

1. $\mathcal{L}_{M}\left\{f^{\prime}(t)\right\}=\sqrt{s} \int_{0}^{\infty} f^{\prime}(t) e^{-s t} d t=\sqrt{s} \lim _{A \rightarrow \infty} \int_{0}^{A} f^{\prime}(t) e^{-s t} d t$

$$
\begin{aligned}
& =\sqrt{s} \lim _{A \rightarrow \infty}\left[\left.f(t) e^{-s t}\right|_{0} ^{A}+s \int_{0}^{A} f(t) e^{-s t} d t\right] \\
& =\sqrt{s}\left(-f(0)+\lim _{A \rightarrow \infty} s \int_{0}^{A} f(t) e^{-s t} d t\right) \\
& =\lim _{A \rightarrow \infty} s \sqrt{s} \int_{0}^{A} f(t) e^{-s t} d t-\sqrt{s} f(0)=s T(s)-\sqrt{s} f(0) .
\end{aligned}
$$

2. $\mathcal{L}_{M}\left\{f^{\prime \prime}(t)\right\}=s^{2} T(s)-s \sqrt{s} f(0)-\sqrt{s} f^{\prime}(0)$.

Misalkan $g(t)=f^{\prime}(t)$ maka $g^{\prime}(t)=f^{\prime \prime}(t)$. Dengan menggunakan Persamaan (4) diperoleh,

$$
\begin{aligned}
\mathcal{L}_{M}\left\{g^{\prime}(t)\right\} & =s \mathcal{L}_{M}\{g(t)\}-\sqrt{s} g(0)=s \mathcal{L}_{M}\left\{f^{\prime}(t)\right\}-\sqrt{s} f^{\prime}(0) \\
& =s(s T(s)-\sqrt{s} f(0))-\sqrt{s} f^{\prime}(0) \\
& =s^{2} T(s)-s \sqrt{s} f(0)-\sqrt{s} f^{\prime}(0) .
\end{aligned}
$$

3. $\mathcal{L}_{M}\left\{f^{(n)}(t)\right\}=s^{n} T(s)-\sqrt{s} \sum_{k=1}^{n} s^{n-k} f^{(k-1)}(0)$.

Pembuktian dilakukan dengan menggunakan induksi matematika.

Misalkan $P$ adalah pernyataan untuk $\mathcal{L}_{M}\left\{f^{(n)}(t)\right\}=s^{n} T(s)-\sqrt{s} \sum_{k=1}^{n} s^{n-k} f^{(k-1)}(0)$.

i) Akan ditunjukkan $P$ bernilai benar untuk $n=1$ yaitu

$$
\mathcal{L}_{M}\left\{f^{\prime}(t)\right\}=s T(s)-\sqrt{s} f(0) .
$$

Berdasarkan Persamaan (4) terbukti bahwa $P$ bernilai benar untuk $n=1$.

ii) Diasumsikan $P$ bernilai benar untuk $n=p$ yaitu

$$
\mathcal{L}_{M}\left\{f^{(p)}(t)\right\}=s^{p} T(s)-\sqrt{s} \sum_{k=1}^{p} s^{p-k} f^{(k-1)}(0)
$$

Kemudian akan ditunjukkan bahwa $P$ bernilai benar untuk $n=p+1$ yaitu

$$
\mathcal{L}_{M}\left\{f^{(p+1)}(t)\right\}=s^{p+1} T(s)-\sqrt{s} \sum_{k=1}^{p+1} s^{p-k+1} f^{(k-1)}(0)
$$

Misalkan $g(t)=f^{(p)}(t)$, maka $g^{\prime}(t)=f^{(p+1)}(t)$ sehingga

$$
\begin{aligned}
\mathcal{L}_{M}\left\{g^{\prime}(t)\right\}= & s \mathcal{L}_{M}\{g(t)\}-\sqrt{s} g(0)=s \mathcal{L}_{M}\left\{f^{(p)}(t)\right\}-\sqrt{s} f^{(p)}(0) \\
& =s\left(s^{p} T(s)-\sqrt{s} \sum_{k=1}^{p} s^{p-k} f^{(k-1)}(0)\right)-\sqrt{s} f^{(p)}(0) \\
& =s^{p+1} T(s)-\sqrt{s} \sum_{k=1}^{p} s^{p-k+1} f^{(k-1)}(0)-\sqrt{s} f^{(p)}(0) \\
& =s^{p+1} T(s)-\sqrt{s} \sum_{k=1}^{p+1} s^{p-k+1} f^{(k-1)}(0) .
\end{aligned}
$$

Dari pernyataan i) dan ii) dapat disimpulkan bahwa Persamaan (6) terbukti benar. 
Teorema 8 (Sifat Integral) Jika $\mathcal{L}_{M}\{f(t)\}=T(s)$, maka transformasi integral $\mathcal{L}_{M}\{f(t)\}$ dari integral $f(t)$ terhadap $t$ adalah

1. $\mathcal{L}_{M}\left\{\int_{0}^{t} f(\tau) d \tau\right\}=\frac{T(s)}{s}$,

2. $\mathcal{L}_{M}\left\{\int_{0}^{t_{1}} \int_{0}^{t_{2}} f(\tau)(d \tau)^{2}\right\}=\frac{T(s)}{s^{2}}$,

3. $\mathcal{L}_{M}\left\{\int_{0}^{t_{1}} \int_{0}^{t_{2}} \ldots \int_{0}^{t_{n}} f(\tau)(d \tau)^{n}\right\}=\frac{T(s)}{s^{n}}$.

\section{Bukti:}

1. Dimisalkan bahwa $g(t)=\int_{0}^{t} f(\tau) d \tau$, maka diperoleh $g(0)=0$ dan $g^{\prime}(t)=f(t)$. Berdasarkan Persamaan (4) diperoleh,

$$
\begin{aligned}
& \mathcal{L}_{M}\{f(t)\}=\mathcal{L}_{M}\left\{g^{\prime}(t)\right\}=s \mathcal{L}_{M}\{g(t)\}-\sqrt{s} g(0) \\
& \mathcal{L}_{M}\{f(t)\}=s \mathcal{L}_{M}\left\{\int_{0}^{t} f(\tau) d \tau\right\} \\
& \mathcal{L}_{M}\left\{\int_{0}^{t} f(\tau) d \tau\right\}=\frac{\mathcal{L}_{M}\{f(t)\}}{s}=\frac{T(s)}{s} .
\end{aligned}
$$

2. Dimisalkan bahwa $g_{2}(t)=\int_{0}^{t_{1}} \int_{0}^{t_{2}} f(\tau)(d \tau)^{2}$, maka diperoleh $g(0)=0, g^{\prime}(0)=0$, dan $g^{\prime \prime}(t)=$ $f(t)$. Berdasarkan Persamaan (5) diperoleh,

$$
\begin{aligned}
& \mathcal{L}_{M}\{f(t)\}=\mathcal{L}_{M}\left\{g^{\prime \prime}(t)\right\}=s^{2} \mathcal{L}_{M}\{g(t)\}-s \sqrt{s} g(0)-\sqrt{s} g^{\prime}(0) \\
& \mathcal{L}_{M}\{f(t)\}=s^{2} \mathcal{L}_{M}\left\{\int_{0}^{t_{1}} \int_{0}^{t_{2}} f(\tau)(d \tau)^{2}\right\} \\
& \mathcal{L}_{M}\left\{\int_{0}^{t_{1}} \int_{0}^{t_{2}} f(\tau)(d \tau)^{2}\right\}=\frac{\mathcal{L}_{M}\{f(t)\}}{s^{2}},
\end{aligned}
$$

3. $\mathcal{L}_{M}\left\{\int_{0}^{t_{1}} \int_{0}^{t_{2}} \ldots \int_{0}^{t_{n}} f(\tau)(d \tau)^{n}\right\}=\frac{T(s)}{s^{n}}$.

Pembuktian dilakukan dengan menggunakan induksi matematika.

Misalkan $Q$ adalah pernyataan untuk $T_{n}(s)=\mathcal{L}_{M}\left\{\int_{0}^{t_{1}} \int_{0}^{t_{2}} \ldots \int_{0}^{t_{n}} f(\tau)(d \tau)^{n}\right\}=\frac{T(s)}{s^{n}}$.

i) Akan ditunjukkan bahwa $Q$ bernilai benar untuk $n=1$ yaitu

$$
\mathcal{L}_{M}\left\{\int_{0}^{t} f(\tau) d \tau\right\}=\frac{T(s)}{s} .
$$

Berdasarkan Persamaan (7) terbukti bahwa $Q$ bernilai benar untuk $n=1$.

ii) Diasumsikan $Q$ benar untuk $n=q$ yaitu

$$
T_{q}(s)=\mathcal{L}_{M}\left\{\int_{0}^{t_{1}} \int_{0}^{t_{2}} \ldots \int_{0}^{t_{q}} f(\tau)(d \tau)^{q}\right\}=\frac{T(s)}{s^{q}} .
$$

Selanjutnya akan dibuktikan bahwa $Q$ bernilai benar untuk $n=q+1$ yaitu

$$
T_{q+1}(s)=\mathcal{L}_{M}\left\{\int_{0}^{t_{1}} \int_{0}^{t_{2}} \ldots \int_{0}^{t_{q+1}} f(\tau)(d \tau)^{q+1}\right\}=\frac{T(s)}{s^{q+1}} .
$$

Misalkan $g_{n+1}(t)=\int_{0}^{t_{1}} \int_{0}^{t_{2}} \ldots \int_{0}^{t_{q+1}} f(\tau)(d \tau)^{q+1}$, maka diperoleh $g_{n+1}(0)=0$ dan $g_{n+1}^{\prime}(t)=$ $g_{n}(t)=\int_{0}^{t_{1}} \int_{0}^{t_{2}} \ldots \int_{0}^{t_{q}} f(\tau)(d \tau)^{q}$. Berdasarkan Persamaan (4) diperoleh,

$$
\begin{aligned}
& \mathcal{L}_{M}\left\{g_{n+1}^{\prime}(t)\right\}=\mathcal{L}_{M}\left\{g_{n}(t)\right\}=s \mathcal{L}_{M}\left\{g_{n+1}(t)\right\}-\sqrt{s} g_{n+1}(0) \\
& \mathcal{L}_{M}\left\{\int_{0}^{t_{1}} \int_{0}^{t_{2}} \cdots \int_{0}^{t_{q}} f(\tau)(d \tau)^{q}\right\}=s \mathcal{L}_{M}\left\{\int_{0}^{t_{1}} \int_{0}^{t_{2}} \ldots \int_{0}^{t_{q+1}} f(\tau)(d \tau)^{q+1}\right\} \\
& \mathcal{L}_{M}\left\{\int_{0}^{t_{1}} \int_{0}^{t_{2}} \cdots \int_{0}^{t_{q+1}} f(\tau)(d \tau)^{q+1}\right\}=\frac{\mathcal{L}_{M}\left\{\int_{0}^{t_{1}} \int_{0}^{t_{2}} \ldots \int_{0}^{t_{q+1}} f(\tau)(d \tau)^{q}\right\}}{s} \\
& \mathcal{L}_{M}\left\{\int_{0}^{t_{1}} \int_{0}^{t_{2}} \ldots \int_{0}^{t_{q+1}} f(\tau)(d \tau)^{q+1}\right\}=T_{q+1}(s)=\frac{T(s)}{s^{q+1}}
\end{aligned}
$$

Dari pernyataan i) dan ii) dapat disimpulkan bahwa Persamaan (8) terbukti benar.

Teorema 9 (Sifat Translasi Pertama) Jika $\mathcal{L}_{M}\{f(t)\}=T(s), \operatorname{maka} \mathcal{L}_{M}\left\{e^{-a t} f(t)\right\}=\frac{\sqrt{s}}{\sqrt{s+a}} T(s+a)$ dengan a adalah konstanta bilangan real dan $s+a>0$.

Bukti:

$$
\mathcal{L}_{M}\left\{e^{-a t} f(t)\right\}=\sqrt{s} \int_{0}^{\infty} e^{-a t} f(t) e^{-s t} d t=\sqrt{s} \int_{0}^{\infty} f(t) e^{-(s+a) t} d t
$$




$$
\begin{aligned}
& \text { Dimisalkan } w=s+a \text { maka } s=w-a \text { sehingga } \\
& \mathcal{L}_{M}\left\{e^{-a t} f(t)\right\}=\sqrt{w-a} \int_{0}^{\infty} f(t) e^{-w t} d t=\frac{\sqrt{w-a}}{\sqrt{w}} \cdot \sqrt{w} \int_{0}^{\infty} f(t) e^{-w t} d t \\
& \mathcal{L}_{M}\left\{e^{-a t} f(t)\right\}=\frac{\sqrt{w-a}}{\sqrt{w}} T(w) \\
& \mathcal{L}_{M}\left\{e^{-a t} f(t)\right\}=\frac{\sqrt{s}}{\sqrt{s+a}} T(s+a) .
\end{aligned}
$$

Teorema 10 (Sifat Translasi Kedua) Jika $\mathcal{L}_{M}\{f(t)\}=T(s)$, maka sifat translasi kedua berbentuk

$$
\mathcal{L}_{M}\{f(t-a) H(t-a)\}=e^{-s a} T(s)
$$

dengan $a>0$ dan $H(t-a)$ merupakan fungsi unit langkah satuan Heaviside yang didefinisikan dengan

Bukti:

$$
H(t-a)= \begin{cases}1, & t>a \\ 0, & t<a\end{cases}
$$

$$
\begin{aligned}
\mathcal{L}_{M}\{f(t-a) H(t-a)\}= & \sqrt{s} \int_{0}^{\infty} f(t-a) H(t-a) e^{-s t} d t \\
& =\sqrt{s} \int_{0}^{\infty} f(t-a) e^{-s t} d t
\end{aligned}
$$

Dimisalkan bahwa $t-a=\tau$ maka $d t=d \tau$ sehinga diperoleh

$$
\begin{aligned}
\mathcal{L}_{M}\{f(\tau) H(\tau)\} & =\sqrt{s} \int_{0}^{\infty} f(\tau) e^{-s(\tau+a)} d \tau=\sqrt{s} \int_{0}^{\infty} f(\tau) e^{-s \tau} e^{-s a} d \tau \\
& =e^{-s a} \sqrt{s} \int_{0}^{\infty} f(\tau) e^{-s \tau} d \tau=e^{-s a} T(s) .
\end{aligned}
$$

Teorema 11 (Sifat Konvolusi) Jika $\mathcal{L}_{m}\{f(t)\}=F(s)$ dan $\mathcal{L}_{m}\{g(t)\}=G(s)$ dengan $F(s)$ dan $G(s)$ merupakan Transformasi Laplace modifikasi dari masing-masing fungsi $f(t)$ dan $g(t)$, maka konvolusi Transformasi Laplace modifikasi dari $f(t)$ dan $g(t)$ adalah

$$
\mathcal{L}_{M}\{(f * g)(t)\}=\frac{1}{\sqrt{s}} \mathcal{L}_{m}\{f(t)\} \mathcal{L}_{m}\{g(t)\}=\frac{1}{\sqrt{s}} F(s) G(s)
$$

dengan $(f * g)(t)$ merupakan konvolusi pada fungsi $f(t)$ dan $g(t)$ dan didefinisikan dengan integral

$$
(f * g)(t)=\int_{0}^{t} f(t-\tau) g(\tau) d \tau
$$

Persamaan integral ini sering disebut sebagai integral konvolusi dan dinotasikan dengan $(f * g)(t)$.

\section{Bukti:}

Berdasarkan Persamaan (3) diperoleh bahwa

$$
\mathcal{L}_{M}\{(f * g)(t)\}=\sqrt{s} \int_{0}^{\infty} e^{-s t} \int_{0}^{t} f(t-\tau) g(\tau) d \tau d t .
$$

Daerah integrasi pada Persamaan (9) dalam bidang $\tau-t$ diilustrasikan dalam Gambar 1. Integrasi dalam Persamaan (9) pertama dilakukan pada $\tau$ dari $\tau=0$ ke $\tau=t$ pada garis vertikal dan kemudian dari $t=$ 0 ke $\infty$ dengan menggeser garis vertikal dari $t=0$ ke luar untuk menutupi seluruh wilayah dibawah garis $\tau=t$.

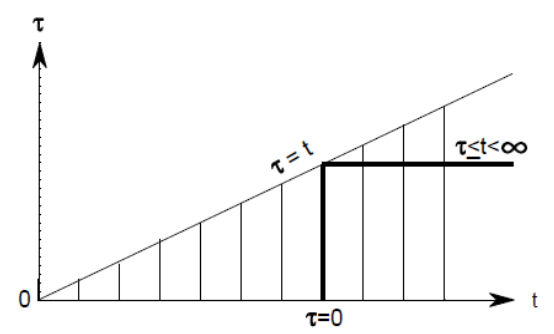

Gambar 1 Daerah integrasi dalam bidang $\tau-t$

Kemudian dengan mengubah urutan integrasi maka diperoleh integrasi pertama dilakukan sepanjang garis horisontal dari $t=\tau$ ke $\infty$ dan kemudian dari $\tau=0$ ke $\infty$ dengan menggeser garis horisontal secara vertikal dari $\tau=0$ ke atas. Dengan demikian Persamaan (9) menjadi

$$
\mathcal{L}_{M}\{(f * g)(t)\}=\sqrt{s} \int_{0}^{\infty} g(\tau) \int_{\tau}^{\infty} e^{-s t} f(t-\tau) d t d \tau .
$$

Kemudian dengan mengganti variabel $t-\tau=x$ dan $d t=d x$ maka diperoleh 


$$
\begin{aligned}
\mathcal{L}_{M}\{(f * g)(t)\} & =\sqrt{s} \int_{0}^{\infty} g(\tau) \int_{0}^{\infty} e^{-s(x+\tau)} f(x) d x d \tau \\
& =\left(\frac{\sqrt{s}}{\sqrt{s}}\right) \sqrt{s} \int_{0}^{\infty} e^{-s \tau} g(\tau) \int_{0}^{\infty} e^{-s x} f(x) d x d \tau \\
& =\left(\frac{\sqrt{s}}{\sqrt{s}}\right) \int_{0}^{\infty} e^{-s x} f(x) d x \sqrt{s} \int_{0}^{\infty} e^{-s \tau} g(\tau) d \tau \\
& =\frac{1}{\sqrt{s}} \mathcal{L}_{m}\{f(x)\} \mathcal{L}_{M}\{g(\tau)\}=\frac{1}{\sqrt{s}} F(s) G(s) .
\end{aligned}
$$

Teorema 12 (Sifat nilai awal) Jika T(s) adalah fungsi hasil Transformasi Laplace modifikasi dari $f(t)$ dan limitnya ada, maka

\section{Bukti:}

$$
\lim _{s \rightarrow \infty} \sqrt{s} T(s)=\lim _{t \rightarrow 0} f(t)
$$

$$
\begin{aligned}
& \lim _{s \rightarrow \infty} \sqrt{s} T(s)=\lim _{t \rightarrow 0} s \int_{0}^{\infty} e^{-s t} f(t) d t \\
& \text { Misalkan } w= \\
& \begin{aligned}
\lim _{s \rightarrow \infty} \sqrt{s} T(s) & =\lim _{s \rightarrow \infty} s \int_{0}^{\infty} e^{-s t} f(t) d t \\
& =\lim _{s \rightarrow \infty} \int_{0}^{\infty} e^{-w} f\left(\frac{w}{s}\right) d w=\int_{0}^{\infty}\left(\lim _{s \rightarrow \infty} f\left(\frac{w}{s}\right)\right) e^{-w} d w \\
& =\int_{0}^{\infty}\left(\lim _{t \rightarrow 0} f(t)\right) e^{-w} d w=\lim _{t \rightarrow 0} f(t) \int_{0}^{\infty} e^{-w} d w=\lim _{t \rightarrow 0} f(t)
\end{aligned}
\end{aligned}
$$

\section{INVERS TRANSFORMASI LAPLACE MODIFIKASI}

Jika Transformasi Laplace modifikasi dari fungsi $f(t)$ adalah $T(s)$ atau $\mathcal{L}_{M}\{f(t)\}$ maka fungsi $f(t)$ adalah invers Transformasi Laplace modifikasi dari $T(s)$ dan disimbolkan dengan $f(t)=\mathcal{L}_{M}^{-1}\{T(s)\}$. Notasi $\mathcal{L}_{M}^{-1}$ merupakan notasi invers dari Transformasi Laplace modifikasi. Hubungan antara fungsi $f(t)$ dan $\mathcal{L}_{M}\{f(t)\}$ dapat dilihat dalam Tabel 1.

Tabel 1. Transformasi Laplace modifikasi pada beberapa fungsi

\begin{tabular}{|c|c|c|}
\hline No. & $\boldsymbol{f}(\boldsymbol{t})$ & $\mathcal{L}_{\boldsymbol{M}}\{\boldsymbol{f}(\boldsymbol{t})\}$ \\
\hline 1. & 1 & $s^{-\frac{1}{2}}$ \\
\hline 2. & $t$ & $s^{-\frac{3}{2}}$ \\
\hline 3. & $t^{n}$ & $n ! s^{-\left(n+\frac{1}{2}\right)}$ \\
\hline 4. & $e^{a t}$ & $\frac{\sqrt{s}}{s-a}$ \\
\hline 5. & $t e^{a t}$ & $\frac{\sqrt{s}}{(s-a)^{2}}$ \\
\hline 6. & $\sin a t$ & $\frac{a \sqrt{s}}{s^{2}+a^{2}}$ \\
\hline 7. & $\cos a t$ & $\frac{s \sqrt{s}}{s^{2}+a^{2}}$ \\
\hline
\end{tabular}

\section{TEOREMA PERKALIAN TERHADAP $t$ BERPANGKAT}

Pada bagian ini dibahas mengenai teorema yang menggambarkan hubungan antara Transformasi Laplace modifikasi terhadap turunannya dalam variabel transformasi. Bentuk hubungan yang dimaksud ditunjukkan dalam Teorema 14. 
Teorema 14 Diberikan $T(s)$ merupakan Transformasi Laplace modifikasi pada fungsi $f(t)$, kemudian transformasi integral $\mathcal{L}_{M}$ pada fungsi $t f(t)$ diberikan dalam bentuk

Bukti:

$$
\mathcal{L}_{M}\{t f(t)\}=-\frac{d}{d s} T(s)+\frac{1}{2 s} T(s) .
$$

$$
\begin{aligned}
\frac{d}{d s} T(s) & =\frac{\partial}{\partial s}\left[\sqrt{s} \int_{0}^{\infty} f(t) e^{-s t} d t\right]=\int_{0}^{\infty} f(t)\left(\frac{\partial}{\partial s} \sqrt{s} e^{-s t}\right) d t \\
& =\int_{0}^{\infty} f(t)\left(\frac{1}{2} s^{-\frac{1}{2}} e^{-s t}-t e^{-s t} s^{\frac{1}{2}}\right) d t \\
& =\int_{0}^{\infty} f(t) \frac{1}{2} s^{-\frac{1}{2}} e^{-s t} d t-\int_{0}^{\infty} f(t) t e^{-s t} s^{\frac{1}{2}} d t \\
& =\frac{1}{2}\left(\frac{1}{\sqrt{s}}\right)\left(\frac{\sqrt{s}}{\sqrt{s}}\right) \int_{0}^{\infty} f(t) e^{-s t} d t-\sqrt{s} \int_{0}^{\infty} t f(t) e^{-s t} d t \\
& =\frac{1}{2 s} T(s)-\mathcal{L}_{M}\{t f(t)\} \\
\mathcal{L}_{M}\{t f(t)\} & =-\frac{d}{d s} T(s)+\frac{1}{2 s} T(s) .
\end{aligned}
$$

Teorema 14 dapat diperluas menjadi beberapa bentuk persamaan sebagai hasil transformasi integral yang memanfaatkan sifat turunan dari fungsi $f(t)$ dan turunan dari transformasi integral $T(s)$ terhadap variabel transformasi seperti dalam Teorema 15.

Teorema 15 Diberikan $T(s)$ merupakan Transformasi Laplace modifikasi pada fungsi $f(t)$, dan $f^{\prime}(t)$ serta $f^{\prime \prime}(t)$ merupakan turunan pertama dan kedua dari fungsi $f(t)$ terhadap $t$, maka

1. $\mathcal{L}_{M}\left\{t f^{\prime}(t)\right\}=-\frac{d}{d s}[s T(s)-\sqrt{s} f(0)]+\frac{1}{2 s}[s T(s)-\sqrt{s} f(0)]$,

2. $\mathcal{L}_{M}\left\{t f^{\prime \prime}(t)\right\}=-\frac{d}{d s}\left[s^{2} T(s)-\sqrt{s} f^{\prime}(0)-s \sqrt{s} f(0)\right]+\frac{1}{2 s}\left[s^{2} T(s)-\sqrt{s} f^{\prime}(0)-s \sqrt{s} f(0)\right]$,

3. $\mathcal{L}_{M}\left\{t^{2} f(t)\right\}=\frac{d^{2}}{d s^{2}} T(s)+\frac{1}{s}\left(-\frac{d}{d s} T(s)+\frac{1}{2 s} T(s)\right)+\frac{1}{4 s^{2}} T(s)$,

4. $\mathcal{L}_{M}\left\{t^{2} f^{\prime}(t)\right\}=\frac{d^{2}}{d s^{2}}[s T(s)-\sqrt{s} f(0)]+\frac{1}{s}\left(-\frac{d}{d s}[s T(s)-\sqrt{s} f(0)]+\frac{1}{2 s}[s T(s)-\sqrt{s} f(0)]\right)+$

$$
\frac{1}{4 s^{2}}[s T(s)-\sqrt{s} f(0)] \text {, }
$$

5. $\mathcal{L}_{M}\left\{t^{2} f^{\prime \prime}(t)\right\}=\frac{d^{2}}{d s^{2}}\left[s^{2} T(s)-\sqrt{s} f^{\prime}(0)-s \sqrt{s} f(0)\right]+\frac{1}{s}\left(-\frac{d}{d s}\left[s^{2} T(s)-\sqrt{s} f^{\prime}(0)-s \sqrt{s} f(0)\right]+\right.$ $\left.\frac{1}{2 s}\left[s^{2} T(s)-\sqrt{s} f^{\prime}(0)-s \sqrt{s} f(0)\right]\right)+\frac{1}{4 s^{2}}\left[s^{2} T(s)-\sqrt{s} f^{\prime}(0)-s \sqrt{s} f(0)\right]$,

6. $\mathcal{L}_{M}\left\{t^{2} f^{\prime \prime \prime}(t)\right\}=\frac{d^{2}}{d s^{2}}\left[s^{3} T(s)-s^{2} \sqrt{s} f(0)-s \sqrt{s} f^{\prime}(0)-\sqrt{s} f^{\prime \prime}(0)\right]+\frac{1}{s}\left(-\frac{d}{d s}\left[s^{3} T(s)-\right.\right.$ $\left.\left.s^{2} \sqrt{s} f(0)-s \sqrt{s} f^{\prime}(0)-\sqrt{s} f^{\prime \prime}(0)\right]+\frac{1}{2 s}\left[s^{3} T(s)-s^{2} \sqrt{s} f(0)-s \sqrt{s} f^{\prime}(0)-\sqrt{s} f^{\prime \prime}(0)\right]\right)+$ $\frac{1}{4 s^{2}}\left[s^{3} T(s)-s^{2} \sqrt{s} f(0)-s \sqrt{s} f^{\prime}(0)-\sqrt{s} f^{\prime \prime}(0)\right]$.

\section{PENERAPAN TRANSFORMASI LAPLACE MODIFIKASI PADA PERSAMAAN}

DIFERENSIAL

Contoh 16 Persamaan diferensial biasa linear orde kedua dengan koefisien konstan

Selesaikan persamaan diferensial berikut.

$$
y^{\prime \prime}-3 y^{\prime}+2 y=4 e^{3 t}, \quad y(0)=-3, y^{\prime}(0)=5 .
$$

Dengan mengaplikasikan transformasi integral $T(s)$ pada soal dan menggunakan nilai awal yang diberikan maka diperoleh,

$$
\begin{aligned}
& \left(s^{2} T(s)-s \sqrt{s} y(0)-\sqrt{s} y^{\prime}(0)\right)-3(s T(s)-\sqrt{s} y(0))+2 T(s)=4 \frac{\sqrt{s}}{s-3} \\
& \left(s^{2} T(s)+3 s \sqrt{s}-5 \sqrt{s}\right)-3(s T(s)+3 \sqrt{s})+2 T(s)=4 \frac{\sqrt{s}}{s-3} \\
& s^{2} T(s)+3 s \sqrt{s}-14 \sqrt{s}-3 s T(s)+2 T(s)=4 \frac{\sqrt{s}}{s-3}
\end{aligned}
$$




$$
\begin{aligned}
& T(s)\left(s^{2}-3 s+2\right)=4 \frac{\sqrt{s}}{s-3}+(-3 s \sqrt{s}+14 \sqrt{s}) \\
& T(s)\left(s^{2}-3 s+2\right)=\frac{4 \sqrt{s}}{s-3}+\frac{-3 s^{2} \sqrt{s}+23 s \sqrt{s}-42 \sqrt{s}}{s-3} \\
& T(s)=\sqrt{s} \cdot\left(\frac{-3 s^{2}+23 s-38}{s-3}\right)\left(\frac{1}{\left(s^{2}-3 s+2\right)}\right) \\
& T(s)=\sqrt{s} \cdot\left(\frac{-3 s^{2}+23 s-38}{s-3}\right)\left(\frac{1}{\left(s^{2}-3 s+2\right)}\right)=\frac{2 \sqrt{s}}{s-3}+\frac{4 \sqrt{s}}{s-2}-\frac{9 \sqrt{s}}{s-1} .
\end{aligned}
$$

Setelah mendapatkan bentuk sederhana dari fungsi hasil transformasi, kemudian Persamaan (10) ditransformasikan dengan invers Transformasi Laplace modifikasi sehingga diperoleh solusi dari persaman diferensial yang diberikan.

$y(t)=\mathcal{L}_{M}^{-1}\left\{\frac{2 \sqrt{s}}{s-3}+\frac{4 \sqrt{s}}{s-2}-\frac{9 \sqrt{s}}{s-1}\right\}=\mathcal{L}_{M}^{-1}\left\{\frac{2 \sqrt{s}}{s-3}\right\}+\mathcal{L}_{M}^{-1}\left\{\frac{4 \sqrt{s}}{s-2}\right\}-\mathcal{L}_{M}^{-1}\left\{\frac{9 \sqrt{s}}{s-1}\right\}=2 e^{3 t}+4 e^{2 t}-9 e^{t}$.

Contoh 17 Persamaan diferensial biasa linear orde ketiga dengan koefisien variabel

Selesaikan persamaan diferensial berikut.

$$
t^{2} y^{\prime \prime \prime}+5 t y^{\prime \prime}+\frac{15}{4} y^{\prime}=t^{3}+2 t^{2}, \quad y(0)=y^{\prime}(0)=y^{\prime \prime}(0)=0 .
$$

Dengan mengaplikasikan transformasi integral $T(s)$ pada soal dan menggunakan nilai awal yang diberikan maka diperoleh,

$\left[s^{3} T^{\prime \prime}(s)+6 s^{2} T^{\prime}(s)+6 s T(s)-s^{2} T^{\prime}(s)-3 s T(s)+\frac{1}{2} s T(s)+\frac{1}{4} s T(s)\right]+\left[-5 s^{2} T^{\prime}(s)-\right.$

$\left.10 s T(s)+\frac{5}{2} s T(s)\right]+\frac{15}{4} s T(s)=\frac{6 \sqrt{s}}{s^{4}}+\frac{4 \sqrt{s}}{s^{3}}$

$s^{3} T^{\prime \prime}(s)=\frac{6 \sqrt{s}}{s^{4}}+\frac{4 \sqrt{s}}{s^{3}}$

$T^{\prime \prime}(s)=\frac{6 \sqrt{s}}{s^{7}}+\frac{4 \sqrt{s}}{s^{6}}$

$T^{\prime}(s)=-\frac{12}{11} s^{-\frac{11}{2}}-\frac{8}{9} s^{-\frac{9}{2}}+C_{6}$

$T(s)=\frac{24}{99} s^{-\frac{9}{2}}+\frac{16}{63} s^{-\frac{7}{2}}+C_{7}=\frac{24}{99} \cdot \frac{\sqrt{s}}{s^{5}}+\frac{16}{23} \cdot \frac{\sqrt{s}}{s^{4}}$

Setelah mendapatkan bentuk sederhana dari fungsi hasil transformasi, kemudian Persamaan (11) ditransformasikan dengan invers Transformasi Laplace modifikasi sehingga diperoleh solusi dari persaman diferensial yang diberikan.

$y(t)=\mathcal{L}_{M}^{-1}\left\{\frac{24}{99} \cdot \frac{\sqrt{s}}{s^{5}}+\frac{16}{23} \cdot \frac{\sqrt{s}}{s^{4}}\right\}=\frac{1}{99} t^{4}+\frac{8}{69} t^{3}$.

Selanjutnya akan ditunjukkan bahwa persamaan diferensial yang diberikan tidak dapat diselesaikan dengan Transformasi Laplace. Dengan mengaplikasikan transformasi integral $F(s)$ pada soal dan menggunakan nilai awal yang diberikan maka diperoleh,

$$
\begin{aligned}
& \frac{d^{2}}{d s^{2}}\left(s^{3} F(s)-s^{2} f(0)-s f^{\prime}(0)-f^{\prime \prime}(0)\right)+5\left(-\frac{d}{d s}\left(s^{2} F(s)-s f(0)-f^{\prime}(0)\right)\right)+ \\
& \frac{15}{4}(s F(s)-f(0))=\frac{6}{s^{4}}+\frac{4}{s^{3}} \\
& \frac{d^{2}}{d s^{2}}\left(s^{3} F(s)\right)+5\left(-\frac{d}{d s}\left(s^{2} F(s)\right)+\frac{15}{4} s F(s)=\frac{6}{s^{4}}+\frac{4}{s^{3}}\right. \\
& \left(s^{3} F^{\prime \prime}(s)+6 s^{2} F^{\prime}(s)+6 s F(s)\right)+\left(-5 s^{2} F^{\prime}(s)-10 s F(s)\right)+\frac{15}{4} s F(s)=\frac{6}{s^{4}}+\frac{4}{s^{3}} \\
& s^{3} F^{\prime \prime}(s)+s^{2} F^{\prime}(s)-\frac{1}{4} s F(s)=\frac{6}{s^{4}}+\frac{4}{s^{3}} .
\end{aligned}
$$

Terlihat bahwa persamaan diferensial hasil transformasi dengan Transformasi Laplace tidak dapat disederhanakan menjadi sebuah fungsi sederhana dan akibatnya persamaan diferensial hasil transformasi tersebut tidak dapat diselesaikan dengan Transformasi Laplace.

\section{PENUTUP}

Transformasi Laplace modifikasi diperoleh dengan melakukan penambahan koefisien dengan variabel transformasi yang sesuai pada persamaan Transformasi Laplace yang dinyatakan dalam bentuk 


$$
\mathcal{L}_{M}\{f(t)\}=T(s)=\sqrt{s} \int_{0}^{\infty} e^{-s t} f(t) d t
$$

dengan $t>0$ dan $e^{-s t}$ merupakan fungsi kernel transformasi serta $s$ merupakan variabel transformasi untuk $s \in \mathbb{R}^{+}$. Transformasi Laplace modifikasi memiliki sifat-sifat seperti operator linear, sifat diferensial, sifat integral, sifat translasi pertama, sifat translasi kedua, sifat konvolusi, dan sifat nilai awal. Selain itu, Transformasi Laplace modifikasi dapat menyelesaikan beberapa persamaan diferensial biasa linear. Pada persamaan diferensial biasa linear dengan koefisien variabel, Transformasi Laplace modifikasi dapat menyelesaikan beberapa persamaan diferensial yang tidak dapat diselesaikan dengan Transformasi Laplace.

\section{DAFTAR PUSTAKA}

[1] Debnath L, Bhatta D. Integral Transform and Their Application Second Edition. Taylor and Francis Group: New York;2007.

[2] Boyce WE, DiPrima RC. Elementary Differential Equations and Boundary Value Problems Seventh Edition. Wiley and Sons: New York; 2001.

[3] Ross, LS. Differential Equations Third Edition. Wiley and Sons: New York; 1984.

[4] Elzaki TM. The New Integral Transform 'Elzaki Transform'. Global Journal of Pure and Applied Mathematics. ISSN 0973-1768, Number 1(2011), pp. 57-64.

[5] Elzaki TM, Elzaki SM, Hilal EMA. Elzaki and Sumudu Transform for Solving Some Differential Equations. Global Journal of Pure and Applied Mathematics. ISSN 0973-1768, Number 2(2012), pp. 167-173.

YUSNANDA

HELMI

YUDHI
: Jurusan Matematika FMIPA UNTAN, Pontianak, yusnanda07@gmail.com

: Jurusan Matematika FMIPA UNTAN, Pontianak, helmi132205@yahoo.co.id

: Jurusan Matematika FMIPA UNTAN, Pontianak, dhye_dhoank@yahoo.co.uk 